\title{
(t)
}

\section{GÊNERO, MARXISMO E SERVIÇO SOCIAL}

\author{
GENDER, MARXISM AND SOCIAL SERVICE
}

\section{Vanessa Bezerra de Souza'}

\section{RESUMO}

O presente artigo trata das desigualdades sociais existentes entre homens e mulheres, conhecidas no debate teórico e político como relações de gênero. Consideramos que o gênero é uma categoria em disputa teórica e política e que as acusações feitas à tradição marxista, acerca de uma pretensa insensibilidade à questão de gênero, não procedem. Trata-se, na verdade, de uma tentativa de desqualificação dessa vertente crítica, visando remeter o problema das relações de gênero a um quadro conceitual nitidamente pós-moderno, em que a articulação entre gênero e classe social é dissolvida. O Serviço Social é abordado a partir de uma perspectiva que conjuga classe e gênero, demonstrando sua utilidade tanto para o entendimento da intervenção e da formação profissional quanto para a análise da própria institucionalização da profissão.

Palavras-chave: Gênero. Marxismo. Serviço Social. Pós-modernidade.

\section{ABSTRACT}

This article discusses the social inequalities between men and women, known in theoretical and political debate as gender relations. We believe that gender is a category in theoretical and political dispute and that the accusations made to Marxist tradition, about a supposed insensitivity to gender, do not proceed. This is an attempt to disqualify this critical stage, aiming to refer the issue of gender relations to a distinctly postmodern conceptual framework in which the articulation between gender and social class is dissolved. Social service is approached from a perspective

1 Professora adjunta da Universidade Federal do Estado do Rio de Janeiro (UNIRIO). E-mail: vanessabezerra@ig.com.br. 


\section{temporalis}

that combines class and gender, demonstrating its usefulness both for understanding the intervention and professional training and for the analysis of the institutionalization of the profession.

Keywords: Gender. Marxism. Social Service. Postmodernity.

Submetido em 15/04/2014

Aceito em 11/07/2014

\section{INTRODUÇÃO}

Abordamos, neste artigo, as desigualdades sociais existentes entre homens e mulheres, conhecidas no debate teórico e político como relações de gênero, fenômeno fundamental para o entendimento do processo de produção e reprodução das relações sociais e, consequentemente, para a formação e intervenção profissional das(os) assistentes sociais.

Tal postura integra um esforço maior de vinculação do gênero ao debate da tradição marxista, visando à construção de uma abordagem "à esquerda", negando argumentos conservadores e fomentando a interlocução com a perspectiva histórica e crítica.

Consideramos que o gênero é uma categoria em disputa, fundamentalmente teórica e política. Em nossa opinião, as acusações feitas à tradição marxista, acerca de uma pretensa insensibilidade à questão de gênero, não têm validade, constituindo-se muito mais como uma tentativa de desqualificação dessa vertente crítica, visando remeter o problema das relações de gênero a um quadro conceitual nitidamente pós-moderno, em que a articulação entre gênero e classe social é dissolvida.

No que diz respeito ao Serviço Social, essa categoria pode ser útil para analisar tanto as práticas interventivas da(o) assistente social quanto a própria configuração do Serviço Social como profissão feminina. Através do estudo das relações de gênero, é possível a realização de análises mais aprofundadas, elaboradas, rigorosas da realidade social, já que o gênero se apresenta como um dos constitutivos dessa realidade e, por isso mesmo, merecedor de atenção. $O$ estudo e a incorporação da categoria gênero às análises da realidade demandam um processo de formação profissional que contemple o seu tratamento, ou seja, uma formação 
que capacite as(os) assistentes sociais a perceberem o gênero presente nas diversas esferas da vida social.

A importância do debate sobre o gênero para o Serviço Social reside no fato de que o atual projeto ético-político da profissão, expresso no código de ética profissional, na lei de regulamentação da profissão e nas diretrizes curriculares, tem como inspiração teórico-política o marxismo, apresentando em um dos princípios do nosso código de ética o compromisso com a defesa da igualdade de gênero: "opção por um projeto profissional vinculado ao processo de construção de uma nova ordem societária, sem dominação-exploração de classe, etnia e gênero". Ora, se o projeto ético-político tem inspiração no marxismo e reconhece que a luta pelo fim das desigualdades de gênero deve ser um dos compromissos das(os) assistentes sociais, compreender o gênero sob uma perspectiva marxista se faz indispensável para uma intervenção crítica, criativa, comprometida, competente e, acrescentaríamos, coerente.

Se gênero vem se constituindo enquanto uma categoria em disputa, inserida nos grandes projetos societários constituídos pelos sujeitos históricos, mulheres e homens, o objetivo deste artigo é o de desmistificar a falsa cegueira do marxismo diante desse fenômeno, reconhecendo, portanto, a importância de as(os) teóricas(os), as(os) militantes e as(os) assistentes sociais marxistas entrarem nessa arena de lutas. Em suma, pretendemos que este trabalho sirva de provocação no sentido de investirmos esforços numa batalha que é tanto teórica quanto ético-política e profissional.

\section{MARXISMO E GÊNERO}

Ao nos debruçarmos sobre a produção teórica que trata das relações sociais de gênero, é possível perceber a presença recorrente da crítica ao marxismo, seja por sua suposta cegueira às questões de gênero, seja pela insuficiência de seu arcabouço categorial para apreender devidamente o fenômeno, muitas vezes sendo analisado por uma perspectiva economicista, em 


\section{temporalis}

que gênero seria o resultado mecânico de exigências impostas pela economia capitalista².

No que diz respeito à própria denominação "marxismo", Netto (1985) lembra que este, da forma que comumente é concebido, nunca existiu. O que ocorreu foi o desenvolvimento de uma tradição teórico-intelectual e política a partir da obra de Marx, tradição marcada por premissas comuns, mas que originou uma pluralidade e diversidade de interpretações, por vezes, inclusive, colidentes. Tal pluralidade de interpretações teve origem na forma como a obra de Marx foi apreendida, passando por reduções, revisões e até mesmo por acréscimos, o que originou a chamada tradição marxista, compreendida por Netto (1985, p. 26) como "um bloco cultural extremamente complexo e diferenciado, no interior do qual se estruturam e se movem vertentes que concorrem entre si".

Diante dessa afirmação, também não procede a acusação de que o marxismo não trata, ou não trata devidamente, a questão das relações de gênero, posto que estamos diante de uma tradição extremamente heterogênea, que certamente justifica a afirmação de que não existe o marxismo, e sim vários marxismos, que compõem a tradição como um todo. A crítica pode proceder, se considerarmos a existência de correntes marxistas que, diante da obra de Marx, comportam-se de maneira dogmática, reducionista e economicista, tomando as análises de Marx como verdades absolutas e a-históricas.

O cerne da diferenciação do marxismo, em relação às outras formas de compreender a realidade, está na ideia apresentada por Marx (1977, p. 103) em suas teses sobre Feuerbach: "Os filósofos só interpretaram o mundo de diferentes maneiras; do que se trata é de transformá-lo". Essa postura diante da investigação sobre a realidade, visando sua transformação, faz da teoria marxista uma teoria revolucionária, o que é fundamental para a compreensão das relações de gênero não apenas como fim em si, mas como meio para sua transformação.

2 Para um maior aprofundamento do debate entre Gênero e Marxismo, conferir: SOUZA, Vanessa Bezerra. Gênero e Marxismo: um estudo sobre suas aproximações. Rio de Janeiro: UFRJ/ESS, 2003. 
Seria um equívoco atribuir apenas aos estudos sobre gênero a crítica à tradição marxista como um todo. Reconhecemos que tal crítica tem origem nas ciências sociais em geral, a partir do caldo de cultura gerado no pós-68, quando foi declarada a "morte" do marxismo diante da nova fase do capitalismo e da ordem burguesa, bem como declarada a "morte" da própria modernidade enquanto projeto civilizacional, sendo apresentado o projeto pós-moderno como arcabouço teórico-conceitual alternativo para a compreensão da realidade e para o estabelecimento de novas formas de organização política.

A maior contribuição da tradição marxista foi o desenvolvimento de sua perspectiva teórico-metodológica, permitindo extrair dos fatos objetivados na vida social os processos que os originam e que os tornam totalidades concretas. Trata-se de um método diante do qual é possível buscar as explicações acerca da superação de algumas de suas próprias análises, já que este compreende a história como detentora de movimento. Sendo assim, se uma análise é feita num dado momento histórico, num momento diferente, por conta de seu movimento, a história demandará novas análises que apreendam suas novas determinações.

A partir do caldo de cultura gerado no pós-68, diversos teóricos, inclusive ditos marxistas, passaram a declarar a falência do marxismo e da modernidade como um todo, criticando categorias fundamentais, tal como a de totalidade, com a acusação de que esta, na verdade, representaria uma postura totalitária, e a categoria de sujeito universal, com a acusação de que esse conceito negava as particularidades dos indivíduos, representando na verdade apenas os interesses daqueles que são dominantes na sociedade, como os homens brancos 3 .

Diante desse quadro, afirmamos que as relações sociais de gênero se constituem enquanto uma categoria em disputa, pelas diversas vertentes teóricas existentes, inclusive pelos(as) teóricos(as) vinculados(as) à pós-modernidade e/ou

3 A crítica ao sujeito universal também foi feita pelas feministas marxistas, contudo, estas argumentavam que tal sujeito deveria ser concebido considerando as particularidades de gênero, ou seja, não negavam, portanto, a existência do sujeito universal em prol dos múltiplos sujeitos específicos, como fazem os pósmodernos. 


\section{temporalis}

ao pós-estruturalismo. É possível dizer que as desigualdades de gênero foram, a princípio, objeto de análise e de preocupação dos(as) marxistas, sendo que, a partir do pós-68, o marxismo foi, aos poucos, perdendo terreno na discussão do gênero, que passou a ser hegemonizada pelas vertentes ligadas à pós-modernidade ${ }^{4}$.

Há que se considerar, portanto, a característica presente em nosso tempo, de disputa entre a razão e o irracionalismo, compreendendo o gênero no interior dessa disputa. Aqui é preciso esclarecer por que afirmamos que as(os) marxistas foram pioneiras(os) na percepção do fenômeno do gênero, já que o fenômeno era tratado como "questão da mulher". Se tomarmos o gênero como um fenômeno histórico e social em ampla articulação com o desenvolvimento e reprodução da sociedade, devendo ser pensado como uma categoria, e se considerarmos que as categorias, segundo o método materialista-histórico de análise da realidade, são portadoras de dois níveis, o gnosiológico e o histórico-ontológico, pode-se dizer que o fenômeno do gênero, no período histórico em que foi apreendido pelos(as) marxistas (final do século XIX e início do século XX), ainda não havia se manifestado em toda a sua complexidade, em parte pela ainda parca organização política das mulheres, o que obviamente limitou a apreensão do fenômeno ou, dito de outra forma, limitou o desenvolvimento da categoria em seu aspecto gnosiológico. Queremos com isso dizer que se a realidade precisa se manifestar primeiramente (aspecto histórico-ontológico), para só depois ser apreendida pelo pensamento através da investigação do(a) pesquisador(a) (aspecto gnosiológico), a descoberta do gênero enquanto relação social não seria possível naquele momento histórico, tendo sido apreendido de maneira parcial, o que não descarta a importância de tais estudos. Preferimos reconhecer, portanto, que o gênero, enquanto fenômeno histórico, foi apreendido de maneira parcial e muitas vezes equivocada pelas(os) marxistas do início do século, tendo sido abordado em sua

4 Para um maior aprofundamento a respeito do debate entre Gênero e Pósmodernidade, conferir: SOUZA, Vanessa Bezerra. 60 anos d'O Segundo Sexo: a (in)visibilidade de Beauvoir no debate sobre as relações de gênero. Rio de Janeiro: UFRJ/ESS, 2010. 
abrangência a partir da complexificação da própria realidade da vida social.

Contudo, não podemos negar, apesar de todas as críticas até aqui feitas, que foram as feministas não marxistas que desenvolveram a compreensão do gênero enquanto fenômeno relacional, que diz respeito tanto às mulheres quanto aos homens, ampliando a análise, até então existente, de que se tratava de exploração e opressão do homem sobre a mulher, o que acabava caindo numa postura maniqueísta, em que as mulheres eram vítimas e os homens os vilões, sem falar nas análises que subsumiam o gênero à questão da exploração de classe, como a de Engels, o que levava à conclusão equivocada de que, no capitalismo, apenas as mulheres burguesas eram oprimidas, apresentando uma visão romântica das relações de gênero no interior da classe trabalhadora, como se nesta houvesse igualdade nas relações de gênero.

Sendo assim, compreendemos que o método materialista é o mais adequado para apreender o gênero, por desenvolver um movimento que, utilizando-se da totalidade e da história, desfetichiza e desnaturaliza os fenômenos sociais. A partir desse método, é possível compreender o gênero como uma categoria que designa o conjunto de fenômenos que expressam um padrão específico de relações existentes entre mulheres e homens, mulheres e mulheres e homens e homens, como aponta Veloso (2003, p. 6):

Tais relações, que em nossa sociedade, são, em sua maioria, marcadas pelas desigualdades, expressam a existência de uma forma determinada de relação entre os diversos sujeitos sociais. Tal padrão de relacionamento é histórico, ou seja, é construído pela própria sociedade, seguindo o seu movimento, pelo conjunto de forças sociais que organizam e dão uma direção a esta mesma sociedade. Deste modo, o gênero não é “natural”, não é fixo, imutável ou intransponível, ao contrário, varia de acordo com as necessidades particulares de cada sociedade e de cada contexto histórico. 


\section{temporalis}

A compreensão das relações de gênero enquanto um fenômeno histórico e social, e não natural, é fundamental para que possamos acreditar na possibilidade de sua transformação, inclusive através da luta pela elaboração e implementação de políticas públicas com enfoque de gênero.

\section{A RESPEITO DA CATEGORIA GÊNERO}

De acordo com Araújo (2000), o conceito de gênero surgiu da necessidade de compreender como a subordinação é reproduzida e a dominação masculina é sustentada em suas múltiplas manifestações, buscando incorporar as dimensões subjetiva e simbólica de poder, para além das fronteiras materiais e das conformações biológicas. A postura de se pensar as práticas materiais paralelamente às questões simbólicas, evitando análises biologicistas e economicistas, tornou possível a utilização desse conceito por feministas marxistas, preocupadas em compreender a permanência de relações desiguais entre mulheres e homens, mesmo em contextos econômicos e políticos diferenciados. Nesse sentido, gênero é considerado como relacional, o que significa dizer que tanto o processo de dominação quanto o de emancipação envolvem relações entre homens e mulheres, tornando as estratégias políticas de transformação como de responsabilidade tanto de homens quanto de mulheres. Tal conceito, segundo a autora, contribuiu para a incorporação na agenda feminista da luta no plano ideológico e cultural, ao reconhecer a importância da subjetividade na construção dos lugares e significados socialmente identificados com o masculino e o feminino.

Almeida (1997), por sua vez, sustenta a importância de não considerar o gênero como um campo específico de estudos, e sim como uma categoria que potencializa a apreensão da complexidade das relações sociais, porque as relações de gênero apresentam-se como um dos fundamentos da organização da vida social. Sendo assim, sua utilização torna-se imprescindível e apenas possível através da análise de determinados processos políticos, econômicos e culturais, não sendo, portanto, possível em análises abstratas das relações entre os sujeitos sociais. Dito de outra maneira, sua utilização se dá por meio da análise de práticas sociais, de preferência em conexão com os processos macropolíticos que 
são tanto constituintes quanto constituídos pelas relações de gênero, o que faz deste uma categoria histórico-analítica.

Veloso (2003, p. 53) entende o gênero como um fenômeno histórico e social, em ampla articulação com o desenvolvimento e reprodução da sociedade, devendo ser tomado como uma categoria, pois expressa modos de ser, ou seja, expressa o padrão de organização de determinada sociedade, ou do ser social. Sendo assim, conclui que as relações de gênero são parte da estrutura e da organização da sociedade, tendo consequências mediatas e imediatas para a reprodução do ser social, o que significa reconhecer o gênero como um elemento fundante da vida social, participando da totalidade social, sendo utilizado para a naturalização de determinados fenômenos sociais como a violência contra a mulher, e acrescentaríamos, para a justificação da própria hierarquia de gênero. $O$ autor considera, portanto, que gênero designa o conjunto de fenômenos que expressam um padrão específico de relações existentes entre mulheres e homens, mulheres e mulheres e homens e homens. Tal padrão de relacionamento é histórico, constituído pela própria sociedade, seguindo o seu movimento, pelo conjunto de forças sociais que organizam e dão direção a essa mesma sociedade.

Saffioti (1994) argumenta que conceber gênero como uma relação entre sujeitos historicamente situados é fundamental para demarcar o campo de batalha e identificar o adversário. Nessas circunstâncias, o inimigo da mulher não é o homem, nem enquanto indivíduo, nem como categoria social, embora seja personificado por ele. O “alvo a atacar” passa a ser, numa concepção relacional, o padrão dominante de relações de gênero. É isso que nos leva a compreender que a violência cometida por uma mulher contra outra pode ser tão produzida pelo gênero quanto a violência exercida por um homem contra uma mulher. Diante dessa assertiva, compreender adequadamente as relações de gênero é conditio sine qua non para a construção de estratégias de luta mais eficazes.

No que se refere à problematização acerca da constituição de uma sociedade justa e igualitária, do ponto de vista das relações de gênero, Garcia (1999) utiliza-se do conceito de 


\section{temporalis}

androginia, através do qual considera necessária a superação das categorias masculino e feminino, com a consequente eliminação do esquema de gênero, dito de outra forma, com o fim dessas categorias enquanto determinantes de uma estruturação social que impõe essas figuras sociais. O autor continua afirmando que as categorias sociais de homem e mulher surgiram por necessidade social, sendo, portanto, determinações sociais, carregando em si seus significados necessários. Para o autor, uma fêmea é uma fêmea, um macho é um macho, e apenas tornam-se mulher e homem num determinado contexto histórico-social, quando foi necessário diferenciar machos e fêmeas numa ordenação hierarquizada. O desaparecimento dessas categorias pressupõe sua desnecessidade social. A partir desse momento, deixará de ser o fator mais importante da constituição da mulher a sua capacidade de gerar um novo ser, atributo natural que até os nossos dias tem significado social importantíssimo na definição da categoria social mulher.

É relevante afirmar que concordamos com a compreensão do gênero enquanto um fenômeno histórico e social que participa da organização da sociedade, constituindo-se dialeticamente através dos processos que compõem a totalidade social. Tal definição explicita o fato de compreendermos o gênero à luz do referencial teórico marxista e, sobretudo, à luz do método materialista histórico e dialético desenvolvido por Marx e amadurecido pela tradição marxista.

\section{AS CONEXÕES ENTRE MARXISMO, FEMINISMO E SERVIÇO SOCIAL}

Acreditamos ser possível e frutífera uma intervenção/formação profissional em Serviço Social que se funde em algumas contribuições do marxismo e do feminismo, desde que suas incorporações se deem de maneira adequada, sem distorções ou vieses de qualquer natureza. A categoria analítica gênero tem um potencial bastante promissor se for incorporada às análises desenvolvidas pelo Serviço Social. Essa profissão, que possui uma influência bastante marcante da tradição marxista, além de ser majoritariamente feminina e de atender usuários(as) cuja maioria é também do sexo feminino, apresenta a característica de 
intervir sobre a produção e reprodução das relações sociais, nas quais estão presentes homens e mulheres, demandando, portanto, uma análise que lhe permita conhecer as relações sociais concretamente.

Reivindica-se, dessa forma, uma postura que, além da incorporação das contribuições da tradição marxista, envolva também algumas das contribuições que a crítica feminista tem oferecido. A questão é que marxistas e feministas vêm (ou pelo menos assim o fizeram em determinado momento) se criticando duramente. Pretende-se apresentar parte do debate sobre a relação entre marxismo e feminismo, apontando algumas das críticas que esse último tem feito ao primeiro e demonstrando que, algumas vezes, tais críticas se baseiam numa noção de marxismo único, no singular, e não em um conjunto de múltiplas ideias, de vertentes diferenciadas e alternativas. Antes, consideram-se necessários alguns apontamentos a respeito da relação entre a tradição marxista e o Serviço Social.

A crítica ao conservadorismo profissional foi fortemente alimentada pela aproximação à tradição marxista, que, então, ofereceria importantes contribuições para o Serviço Social em sua tarefa de renovação profissional, em suas dimensões acadêmicas, políticas e técnico-operativas. No entanto, a primeira aproximação do Serviço Social à tradição marxista, no chamado movimento de reconceituação, ocorreu de maneira marcadamente enviesada, já que as fontes que alimentaram essa aproximação não eram as originais, mas sim intérpretes nem sempre fiéis ao pensamento marxiano.

A reflexão sobre os projetos profissionais remete aos "projetos societários”, os quais, segundo Netto (1999, p. 93), são "projetos que apresentam uma imagem de sociedade a ser construída, que reclamam determinados valores para justificá-la e que privilegiam certos meios (materiais e culturais) para concretizá-la”. São projetos coletivos, macroscópicos, voltados para o conjunto da sociedade; são, ainda, influenciados por "projetos de classe" que refratam determinações de gênero, étnicas, culturais etc. 


\section{temporalis}

Já os projetos profissionais dizem respeito às profissões reguladas juridicamente e supõem uma formação teórica e/ou técnico-interventiva. Tais projetos "apresentam a autoimagem de uma profissão", elegendo os valores que a legitimam socialmente, delimitando seus objetivos e funções, formulando os requisitos para o seu exercício e estabelecendo normas e balizas para a atuação profissional (NETTO, 1999, p. 95).

O sujeito coletivo, ou seja, a categoria profissional, constrói, por meio da sua organização, o seu projeto profissional, o qual se constitui por dimensões que envolvem: profissionais diretamente vinculados ao exercício profissional, docentes e pesquisadores ligados à área da formação e pesquisa e estudantes. Constata-se que a categoria de assistentes sociais apresenta uma forte capacidade de organização, não sendo raro notar, em seus fóruns e eventos, a participação desses "segmentos" do Serviço Social, que, com suas respectivas organizações (conjunto CFESS/ CRESSs, ABEPSS e ENESSO), imprimem a discussões, debates e formulações da categoria profissional um caráter democrático, participativo e amplamente representativo dessa categoria.

Ao mesmo tempo, esse sujeito coletivo não se apresenta, do ponto de vista teórico, político e ideológico, de forma homogênea. Ao contrário, tal sujeito se constitui como uma "unidade "não identitária", que se plasma em um universo heterogêneo cujos membros são, necessariamente, indivíduos diferentes, com origens, expectativas, comportamentos e condições intelectuais amplamente distintas e diversas, o que leva à possibilidade (e, em vários momentos, à efetividade) de surgimento de projetos profissionais variados, vinculados a igualmente variados projetos societários. A categoria profissional, portanto, é um espaço plural, de onde proliferam constantemente projetos profissionais distintos, que, no bojo do debate democrático, se confrontam e se afirmam em maior ou menor grau.

A consolidação do projeto profissional do Serviço Social deve ocorrer em consonância com o respeito a um dos princípios mais caros a esse mesmo projeto, que, inclusive, figura com destaque em nosso Código de Ética Profissional: o pluralismo, o que não significa, em hipótese alguma, a ausência da luta de ideias, do 
confronto de concepções teóricas e políticas e do debate entre os diversos projetos existentes. Significa, sim, que o verdadeiro debate democrático só alcança sua plena realização quando realizado com respeito às hegemonias legitimamente conquistadas, em que este, enquanto princípio democrático, garantiria a própria existência do pluralismo.

O Projeto Ético-Político do Serviço Social apresenta uma estrutura básica que tem em seu núcleo o reconhecimento da liberdade (concebida historicamente como possibilidade de escoIher entre alternativas concretas) como valor central, o que leva tal projeto a assumir um compromisso com a autonomia, a emancipação e a plena expansão dos indivíduos sociais. Fica nítida a vinculação do Projeto Ético-Político do Serviço Social a um determinado projeto societário atento a incidência e centralidade das determinações de classe (mediadas pelo gênero, etnia etc.), que se propõe à construção de uma nova ordem social, à defesa intransigente dos direitos humanos e à recusa do arbítrio e dos preconceitos. Tais propostas imprimem a esse projeto uma clara dimensão política, concretizada no posicionamento em favor da equidade e da justiça social; na perspectiva da universalização do acesso aos bens e serviços relativos aos projetos, programas e políticas sociais; na ampliação e na consolidação da cidadania; e na defesa do aprofundamento da democracia, enquanto socialização da participação política e da riqueza socialmente produzida. Compõe ainda esse projeto o compromisso com a competência profissional, que deve ter como base o aprimoramento intelectual, demandando uma formação acadêmica qualificada, que tenha por base concepções teórico-metodológicas sólidas e críticas que viabilizem uma análise concreta da realidade social.

Como se pode ver, a interlocução do Serviço Social com a tradição marxista gerou importantes contribuições para o processo de amadurecimento profissional, possibilitando à categoria profissional uma abordagem mais crítica e consistente das diversas questões com as quais lidamos cotidianamente. Dentre essas questões, as relações de gênero têm, em nossa opinão, lugar de destaque, constituindo-se como importante categoria para análise e intervenção junto à realidade. 


\section{temporalis}

\section{GENERIFICANDO A PROFISSÃO DE ASSISTENTE SOCIAL}

O Serviço Social está inserido num quadro determinado social e sexualmente. Sua institucionalização se dá no interior dessa lógica, que rege a sociedade e que define a sua natureza enquanto profissão. Atuando no campo da reprodução das relações sociais, o Serviço Social é considerado uma profissão feminina, o que conduziria a um status de subalternidade perante outras profissões. Não se está dizendo que tal subalternização tenha as relações de gênero como determinantes. No entanto, não se pode negar que o gênero e a divisão sexual do trabaIho apresentem uma contribuição essencial na definição dessa característica.

O que se deve ressaltar é que os resultados da ação da(o) assistente social, enquanto sujeito de determinados processos de trabalho, passam necessariamente pelo universo de valores incorporados à trajetória da sua socialização, o que significa que seu trabalho tem implicações subjetivas e que a sua subjetividade influencia o seu trabalho. Ou seja, a intervenção profissional está permeada pelos valores dos sujeitos individuais que se encontram na condição de profissionais. Esse fato exige da formação profissional não apenas uma dimensão informativa, mas também uma dimensão efetivamente formativa, que consiga sucesso na difícil tarefa de fazer com que tais valores passem por um processo de transformação 5 .

Considera-se essencial, no que se refere a essa dimensão formativa, o aprofundamento de estudos referentes às relações de gênero e sua maior inserção na formação profissional da(o) assistente social. A finalidade de tal inserção residiria na maior

5 Não é possível, por exemplo, que a(o) profissional que vai atuar junto a mulheres vítimas de violência doméstica entenda que "se a mulher apanhou é porque alguma coisa ela fez para merecer". Seria impraticável uma boa intervenção profissional junto à população de rua por parte de uma(um) profissional que acredita que "os moradores de rua estão nas ruas porque querem". O trabalho profissional junto a portadores de HIV seria completamente ineficaz se a(o) profissional acreditasse que "a AIDS se pega com um aperto de mãos". Como poderia uma(um) assistente social trabalhar em comunidades carentes se esta(e) possuísse "aversão à miséria"? Essas situações, que infelizmente não são tão fictícias como gostaríamos que fossem, só são evitadas com um processo de formação que contemple uma mudança nos valores que nossa sociedade ainda preconceituosa, injusta e desigual veicula maciçamente. 
capacidade $\mathrm{da}(\mathrm{o})$ profissional de analisar os processos de formação da sociedade, das subjetividades, das ideologias, das diversas práticas sociais, econômicas e políticas, o que teria como consequência uma intervenção profissional mais competente, crítica e eficaz.

Pretendemos apresentar o tratamento dado à categoria analítica gênero pelo Serviço Social, buscando perceber as tendências da sua utilização no debate acadêmico-profissional. O que se percebe é que nem sempre a utilização do termo "gênero" significa a apropriação da categoria analítica "gênero". Esse termo tem sido muito utilizado, sem, contudo, ser acompanhado por uma reflexão aprofundada acerca de seus significados. Não se trata, como aponta Louro (1996, p. 8), de uma "mera mudança de rótulo": em vez de se usar a palavra "mulher" passa-se a utilizar a palavra "gênero", mas de uma nova forma teórico-metodológica de se abordar a questão das desigualdades entre homens e mulheres. Gênero corresponde ao processo histórico e social de transformação dos sujeitos em homens ou mulheres, situando-os em condições determinadas no interior de uma sociedade marcada por particularidades e especificidades de gênero. Trata-se, portanto, de uma sociedade "generificada".

Entende-se que o gênero está presente cotidianamente na sociedade e o seu entendimento torna-se ímpar para a(o) assistente social. O fato de o gênero ser um dos elementos constitutivos das relações sociais nos coloca a demanda de investimento no que tange ao seu estudo e entendimento. Apesar de nem sempre serem percebidas, as relações de gênero fazem parte do cotidiano profissional da(o) assistente social, que deve ter, por isso, uma formação que dê subsídios para a realização de uma análise capaz de desvendar o conjunto das relações sociais nas quais se inscreve.

O Serviço Social está inserido tanto em uma divisão social do trabalho quanto em uma divisão sexual do trabalho ${ }^{6}$, tendo esta

6 Não se trata de duas divisões isoladas e excludentes. Divisão social do trabalho e divisão sexual do trabalho são pensadas como um fenômeno único e indissolúvel, já que as representações que se fazem a respeito do masculino e do feminino são necessariamente sociais. Rejeita-se, dessa forma, qualquer ideia que leve ao entendimento de que haja duas divisões separadas, uma social 


\section{temporalis}

como base a subalternidade da mulher em relação ao homem. O fato de o Serviço Social ser uma "profissão feminina"7 nos leva a supor que o gênero tem um papel importante na definição da profissão, não simplesmente por ela ser composta majoritariamente por mulheres, mas por haver, tradicionalmente, uma designação social das mulheres a essa carreira.

$A(O)$ profissional de Serviço Social trabalha no relacionamento direto com o outro, no plano das relações interpessoais, já que ela(e) encontra-se, institucionalmente, no nível da reprodução das relações sociais. Esse relacionamento profissional não deveria, em hipótese alguma, ser realizado desprovido de um processo de análise e reflexão sobre tais relações. No nosso entender, é necessário que as(os) profissionais conheçam o terreno em que estão pisando e sobre o qual irão avançar em seu cotidiano profissional. O gênero é uma parte relevante desse "terreno" e, exatamente por isso, a sua reflexão deve estar amplamente presente na agenda de debates da categoria de assistentes sociais, contribuindo para a intervenção profissional crítica, criativa, competente e comprometida com as(os) usuárias(os). A partir desse ponto de vista, considera-se que deixar de privilegiar, tanto na intervenção quanto na formação profissional, a reflexão crítica sobre as relações de gênero tem por consequência prejuízos expressivos a uma atuação efetivamente voltada aos interesses das(os) usuárias(os) dos serviços prestados por nossa categoria.

\section{CONSIDERAÇÕES FINAIS}

De acordo com lamamoto (1998, p. 20), entre os desafios vividos pelas(os) assistentes sociais, está o desenvolvimento de sua capacidade de "decifrar a realidade e construir propostas de trabalho criativas e capazes de preservar e efetivar direitos, a partir de demandas emergentes no cotidiano". Para se decifrar a realidade de maneira abrangente, a utilização do potencial analítico que o gênero oferece mostra-se fundamental. É sempre

e outra sexual. Ambas se interpenetram e se constroem mutuamente.

7 Acredita-se que o que torna o Serviço Social uma profissão feminina não é apenas o fato de essa profissão ter um número muito maior de mulheres nos quadros estudantis ou profissionais, mas também o fato de sua materialidade ser um atributo social tradicionalmente designado às mulheres. 
bom observar, entretanto, que não se pretende a utilização desse referencial teórico de maneira absolutizada ou, ainda, estabelecer hierarquias entre os eixos básicos que estruturam a realidade social. O que se afirma é a necessidade de se perceber a articulação entre esses eixos; para tanto, a categoria gênero se demonstra de grande utilidade.

É possível perceber que a categoria gênero, entendida como um fenômeno social que estabelece os diversos padrões de comportamento entre homens e mulheres, vem sendo consideravelmente utilizada pelo Serviço Social. A partir do final da década de 1980, com o surgimento dos primeiros trabalhos que se dedicavam ao estudo das mulheres, ou mais precisamente, à intervenção do Serviço Social junto a elas, é possível constatar a incorporação dessa categoria ao vocabulário analítico das(os) assistentes sociais. Desde então, seu uso no debate e reflexão sobre as diversas questões que se colocam em nosso cotidiano profissional, em várias áreas de intervenção, apresentou um incremento significativo.

A categoria analítica gênero tem sido utilizada nos trabaIhos produzidos pelo Serviço Social para discutir as desigualdades existentes entre homens e mulheres, enfatizando a condição subordinada dessas últimas na sociedade. O exame da produção do Serviço Social brasileiro ao longo das últimas décadas permitiu constatar que a categoria foi usada pelo Serviço Social para refletir acerca de determinados fenômenos sociais (violência, trabalho, saúde, cidadania, movimentos sociais, família etc.), tendo por objetivo a elaboração de propostas que visassem à melhoria das condições de vida das mulheres, seja através da formulação e implantação de políticas públicas a elas destinadas, seja através da redefinição do padrão vigente de relações de gênero.

Essa categoria pode ser útil para analisar tanto as práticas interventivas $\mathrm{da}(\mathrm{o})$ assistente social quanto a própria configuração do Serviço Social como profissão, que possui, em nossa opinião, não um perfil feminino, mas sim um número esmagador de agentes profissionais do sexo feminino. Julgamos importante atentar para esse aspecto para que não se caia na armadilha de tomar as características da(os) agentes profissionais como 


\section{tempordils}

características da profissão, embora as representações sobre essa última sejam fortemente marcadas pelas representações que se tem das(os) primeiras(os). Atribuir a determinadas profissões o caráter de feminina significa admitir a existência do polo oposto, ou seja, a existência das chamadas profissões masculinas, que estariam interditadas ao exercício das mulheres. A recusa ao essencialismo, ou seja, à postura de se acreditar que existam lugares naturalmente femininos ou naturalmente masculinos, é fundamental para que se possa alcançar o real entendimento do gênero e das suas consequências para a organização da vida social.

\section{REFERÊNCIAS}

ALMEIDA, Sueli Souza. Relações de gênero: notas preliminares para análise de seu potencial heurístico. Rio de Janeiro: UFRJ, 1997.

ARAÚJO, Clara. Marxismo, feminismo e o enfoque de gênero. Revista Crítica Marxista, São Paulo, n. 10, 2000.

CFESS. Código de Ética Profissional do Assistente Social. In: BONETTI, Dilséia et al. Serviço Social e ética. São Paulo: Cortez/ CFESS, 1996.

- Assistentes Sociais no Brasil: elementos para o estudo do perfil profissional. Brasília: CFESS, 2005.

GARCIA, Francisco Montero. Ser Social, Dominação e Violência: um estudo do binômio dominação-violência a partir de uma perspectiva ontológica, com ênfase na questão de gênero. São Paulo: PUC-SP, 1999.

IAMAMOTO, M. V. O Serviço Social na Contemporaneidade: trabalho e formação profissional. São Paulo: Cortez, 1998.

LOURO, Guacira Lopes. Nas redes do conceito de gênero. In: LOPES, Marta Julia Marques; MEYER, Dagmar Estermann; WALDOW, Vera Regina (Org.). Gênero e saúde. Porto Alegre: Artmed, 1996. p. 7-18. 
MARX, K. Teses sobre Feuerbach. In: MARX, K.; ENGELS, F. Textos 1. São Paulo: Sociais, 1977. p. 125-128

NETTO, J. P. O que é marxismo. São Paulo: Brasiliense, 1985.

. A construção do projeto ético-político do Serviço Social frente à crise contemporânea. In: Capacitação em Serviço Social e Política Social. Módulo 1 - Brasília: CEAD/ABEPSS/CFESS, 1999. p. 91-111.

SAFFIOTI, Heleieth lara Bongiovani. Posfácio: conceituando o gênero. In: SAFFIOTI, H. I. B.; MUÑOZ-VARGAS, M. (Org.). Mulher brasileira é assim. Rio de Janeiro: Rosa dos Tempos: NIPAS; Brasília: UNICEF, 1994. p. 271-283.

VELOSO, Renato. Notas introdutórias sobre o debate das relações de gênero. Revista Universidade e Sociedade. São Paulo: Sindicato Nacional dos Docentes das Instituições de Ensino Superior, 2003. 